\title{
FORMAÇÃO DE PROFESSORES E A PRÁTICA NA EDUCAÇÃO BÁSICA, NO CONTEXTO DA EDUCAÇÃO INCLUSIVA
}

\author{
GUASSELLI, Maristela ${ }^{1}$
}

\section{INTRODUÇÃO}

Este trabalho é parte do estudo de doutorado ${ }^{2}$ que analisa as relações que se estabelecem entre o campo epistemológico da formação continuada e a forma como os professores racionalizam este conhecimento no cotidiano da educação básica, buscando identificar se os conhecimentos têm contribuído para a docência, como também os aspectos que motivam os professores da educação básica a buscarem formação continuada em educação especial.

Investiga resultados de uma política de formação de professores, que é um tema emergente, no mundo ocidental contemporâneo; uma prática defendida como projeto de nação, articulada em regime de colaboração, na intenção de criar elementos constitutivos para operacionalizar diretrizes, visando à implementação de programas de formação inicial e continuada que expressem dinâmicas pedagógicas articuladas à valorização dos profissionais da educação.

A abordagem desenvolvida neste estudo é de natureza qualitativa, tendo o processo de investigação fundamentado na Análise de Discurso (AD), considerando que a mesma não estaciona na interpretação, mas trabalha seus limites, seus mecanismos, como parte dos processos de significação.

Nas etapas do processo de investigação, o exercício de descrição, interpretação e significação foi uma constante, com o objetivo de entender o modo como os sujeitos da pesquisa dão significado ao seu próprio fazer no contexto em que estão inseridos, permitindo, assim, que dessem sentido às suas ações nas relações que se estabelecem entre o campo epistemológico da formação continuada em educação especial e a forma como racionalizam esse conhecimento na educação básica, independentemente dos cargos e funções que ocupam.

\footnotetext{
${ }^{1}$ Doutora em Educação pela UFRGS - maristelaguasselli@gmail.com

${ }^{2}$ Este artigo é parte do estudo da Tese "Formação Continuada na Perspectiva da Educação Inclusiva: Epistemologia e Prática", desenvolvido na linha de pesquisa Universidade: Teoria e Prática, mais especificamente no campo da formação de professores, do PPGDU/UFRGS como requisito de curso de doutorado, tendo como Orientadora a Prof ${ }^{a}$ Doutora Elizabeth D. Krahe.
} 
Existe um conjunto de noções que sustentam a possibilidade de análise: discursos, sentidos, linguagem, sujeito e ideologia que constituiu o corpus da pesquisa, com base na análise documental; entrevista semiestruturada; descrição das etapas do material empírico recolhido: Análise do material coletado e construção de categorias; Descrição/interpretação do objeto de análise e cruzamento com o referencial teórico.

A pesquisa analisou uma interface entre a produção de conhecimento na universidade e a prática na escola de ensino regular, com foco na formação continuada em educação especial e a relação com o trabalho docente na educação básica. Traz questionamentos acerca dos saberes que constituem as práticas dos professores e suas decisões pedagógicas, após realização de curso de Pós-Graduação em Educação - Lato Sensu - Especialização em Educação Inclusiva, em uma universidade comunitária da região metropolitana de Porto Alegre no RS. Os sujeitos principais da pesquisa foram 16 professoras/alunas concluintes do referido curso. Os dados foram coletados em entrevistas com as professoras, investigando sobre seus fazeres no contexto em que estão inseridas, possibilitando que dessem sentido às suas ações nas relações que estabelecem entre o campo epistemológico da formação continuada em educação especial e a forma como racionalizam esse conhecimento na educação básica.

No corpus da análise encontrei conjuntos discursivos que evidentemente não se apresentam como unidade, ocasião em que coloco em destaque dois grandes enfoques: o primeiro deles refere-se à legislação nacional, com suas nuances nas esferas estaduais e municipais, especialmente por estarem atreladas à lei maior. Buscam medidas possíveis, nem sempre as necessárias, para assegurar uma educação de qualidade. No discurso das professoras alunas há uma sinalização que vai além da conotação linguística, indicando como os sentidos vêm se constituindo em relação às políticas públicas referentes à formação de professores e à educação especial na educação básica, permeados pela (não) valorização da carreira docente.

O segundo destaque se refere ao modo como as professoras alunas significam, problematizam e evidenciam as contribuições da formação continuada no âmbito da educação especial e a (não) relação com o trabalho docente, com a ação pedagógica em sala de aula na educação básica. Em decorrência, deixo o vestígio, porém de forma tênue, de que este fato pode estar relacionado à participação na formação continuada, resultando na especialização em educação inclusiva. A partir das repostas obtidas nas entrevistas com as professoras alunas, agora especialistas, é 
possível também inferir que a busca de especialização pode ser um caminho para sair da função docente.

Estes enfoques vão sendo permeados por outros discursos, marcando suas aproximações e ou distanciamentos que foram descritos dentro de quatro eixos ${ }^{3}$ principais, os quais, pela amplitude do tema, não serão apresentados neste artigo.

Dito isso, considero importante evidenciar que aqui farei um recorte que retrata parte da pesquisa, apontando momentos e movimentos da formação continuada, trazendo elementos para pensarmos a formação e o lugar que o professor ocupa neste contexto, conforme passo a descrever a seguir.

\title{
EPISTEMOLOGIA E PRÁTICA
}

\begin{abstract}
O saber dos professores não é um 'foro íntimo' povoados de representações mentais, mas um saber sempre ligado a uma situação de trabalho com outros (alunos, colegas, pais, etc.), um saber ancorado numa tarefa complexa (ensinar), situado num espaço de trabalho (a sala de aula, a escola), enraizado numa instituição e numa sociedade. (TARDIF, 2007, p. 15, grifo do autor).
\end{abstract}

Abro esse tema com as palavras de Tardif (2007) que permitirão ressaltar dois elementos essenciais em minha argumentação. $O$ primeiro se refere ao movimento de profissionalização que busca renovar os fundamentos epistemológicos do ofício de professor, e nesta perspectiva o autor afirma que a questão da epistemologia da prática profissional encontra-se no cerne do movimento de profissionalização, ou seja, "em grande parte, a natureza dos conhecimentos que estão em jogo" (TARDIF, 2007, p. 247), situados no âmbito do conhecimento dos profissionais tais como médicos, professores, entre outras profissões que fazem parte desses objetos epistemológicos.

E de igual modo, o segundo se refere à transmissão e produção dos saberes que "a epistemologia passa progressivamente de teoria do conhecimento a teoria da ciência, e mais especificamente às ciências empíricas da natureza" (TARDIF, 2007, p. 254), ressaltando que a epistemologia da prática profissional é um conjunto de saberes mobilizados e utilizados pelos profissionais para desempenhar todas as suas tarefas em seu espaço de trabalho. Diante disso, é o que apresento na seção seguinte.

\footnotetext{
${ }^{3}$ Ver- GUASSELLI, Maristela Ferrari Ruy. Formação Continuada na Perspectiva da Educação Inclusiva: Epistemologia e Prática. Tese (Doutorado em Educação) - Universidade Federal do Rio Grande do Sul, Programa de Pós-Graduação em Educação, Porto Alegre, BR-RS, 2014.
} 


\title{
ESPECIALIZAÇÃO E AUTONOMIA DOCENTE
}

O foco central dessa seção é apresentar as vozes das professoras alunas, agora especialistas em educação inclusiva, a partir do que orientou as discussões e reflexões geradas no contexto da educação básica, ao longo de suas atividades, estabelecidas a partir do curso de especialização. $O$ destaque é a formação continuada em educação especial e a relação com o trabalho docente na educação básica. Procuro evidenciar a forma como as professoras alunas significam o campo epistemológico da formação continuada em educação especial na contribuição para as decisões pedagógicas, no cotidiano da educação básica.

Nesta perspectiva Nóvoa $(2001$, p. 2) nos faz refletir ao afirmar que "não basta deter conhecimento para o saber transmitir a alguém, é preciso compreender o conhecimento, ser capaz de o reorganizar, ser capaz de o reelaborar e de transpô-lo em situação didática em sala de aula."

Segundo Isaia e Bolzan (2011, p. 187), "não é possível compreendermos a construção da docência sem levarmos em conta os processos de aprendizagem que a permeiam. Ambos os processos repercutem na produção de ser e de se fazer professor." Nesse sentido as autoras dizem que a docência é tecida por movimentos constitutivos da aprendizagem, que resultam em diferentes tipos de professores a qual denominam de "professoralidade".

\begin{abstract}
Processo que se orienta para a constante apropriação de conhecimentos/saberes/fazeres próprios à área de atuação de cada profissão, para os quais as ideias de conhecimento pedagógico compartilhado e redes de interações são imprescindíveis. Implica também na sensibilidade do docente como pessoa e profissional em termos de atitudes e valores, tendo a reflexão como componente intrínseco ao processo de ensinar, de aprender, de formarse e, consequentemente, de desenhar sua própria trajetória. A professoralidade instaura-se ao longo de um percurso que engloba de forma integrada as ideias de trajetória e de formação, consubstanciadas no que costumamos denominar de trajetórias formativas. (ISAIA; BOLZAN, 2011, p. 187, grifo das autoras).
\end{abstract}

De um modo geral, a partir das respostas obtidas nas entrevistas, observase que o curso foi significativo tanto para a ação pedagógica no cotidiano escolar quanto para o crescimento pessoal e profissional, gerando por vezes avanços, por outras rupturas e resistências que são representadas e atribuídas por suas práticas, possibilitando a explicitação de fatores que modificaram suas decisões e/ou justificaram, fortaleceram a manutenção de suas práticas. 
Questionadas acerca da influência desta formação continuada no trabalho docente, destacam que, a partir da experiência adquirida na educação básica, foi possível subsidiar o diálogo no curso de especialização, como também ficou evidente o fortalecimento em relação à possibilidade de migrarem ou manterem cargos de gestoras (diretora, coordenadora, professora do núcleo de apoio pedagógico) no contexto da educação básica, tal como afirma Nóvoa (2001, p. 3), dizendo que é preciso criar lógicas de trabalho coletivo, "através da reflexão, através da troca de experiências, através da partilha", a partir das quais seja possível dar origem a uma atitude reflexiva da parte dos professores, escrevendo ainda que

a experiência é muito importante, mas a experiência de cada um só se transforma em conhecimento através da análise sistemática das práticas. Uma análise que é análise individual, mas que também é coletiva, ou seja, feita com os colegas, nas escolas e em situações de formação. (NÓVOA, 2001, p.3).

É o que os enunciados dos sujeitos da pesquisa confirmam quando se referem aos colegas de curso/grupo, indicando que estão valorizando a sua aprendizagem no coletivo. Indicando que a formação pode sim fazer a diferença na sua prática e apesar das leituras e trabalhos realizados na especialização terem contribuído, desponta também a questão do olhar, da colaboração e do confronto entre os saberes produzidos pela experiência coletiva. Estes, por sua vez, estão relacionados com a carreira e a socialização profissional e indicam uma mudança de postura a partir do conhecimento adquirido em um coletivo, quando argumentam que a troca entre colegas e experiências muito contribuíram para a aprendizagem individual.

Segundo as autoras, "o modelo assenta-se na profissionalidade docente, ou seja, no conjunto das competências adquiridas pela formação e por um (a) profissional, reconhecidas socialmente como características de determinada profissão". (GATTI, BARRETO; ANDRÉ 2011, p. 43).

Nesta perspectiva, a formação pode estar sendo reduzida apenas ao seu caráter prático, ausentando de maneira significativa a relação que determinados docentes fazem entre teoria e prática, como também expressa sobre a historicidade que se imprime mais especificamente aos saberes adquiridos no início da carreira, referente aos saberes experiências que são reativados na 
[...] sua trajetória social e profissional ocasiona-lhes custos existenciais (formação profissional, inserção na profissão, choque com a realidade, aprendizagem na prática, descoberta de seus limites, negociação com os outros, etc.) e é graças aos seus recursos pessoais que podem encarar esses custos e assumi-los. (TARDIF, 2007, p. 107, grifo do autor).

Contudo, o processo de construção do conhecimento desenvolve-se na interação com a realidade do meio social em que está inserido, colocando em prática suas capacidades pessoais. Na premissa reiterada por Tardif (2007), a experiência da prática profissional é crucial na aquisição das rotinas de trabalho e sentimento de competência na estruturação de sua prática, que se transformam muito cedo em certezas profissionais ao dizer que "o saber do professor traz em si mesmo as marcas de seu trabalho, mas é produzido e modelado no e pelo trabalho." (TARDIF, 2007, p.17)

Quanto à estrutura curricular, qualidade docente e organização do curso de especialização, de um modo geral foi entendido como positivo com destaques, antes de tudo, aos subsídios e possibilidade de ter elementos, a partir das aulas na especialização, para debater e apoiar colegas e famílias no contexto da escola em que trabalham, contribuindo para uma maior compreensão e contextualização dos problemas nessas modalidades de ensino.

Outro indicativo apresenta-se em torno do conhecimento adquirido pelas trocas de experiências e desafios dos professores. As experiências dos colegas de curso enriqueciam e incrementavam as reflexões no processo formativo, colocando em relevância o fato de poderem expressar seu conhecimento no espaço de trabalho, dando destaque ao momento coletivo e relações interpessoais.

\section{A REPERCUSSÃO DA ESPECIALIZAÇÃO NO CONTEXTO ESCOLAR}

Nesta seção, uma constatação geral se destaca nos excertos na medida em que as professoras alunas referem-se a sua história de vida emocional, pessoal, afetiva e interpessoal, e não só como um sujeito epistêmico que busca em sua memória "representações a partir das quais organiza as novas informações." (TARDIF, 2007, p. 103).

Contudo, Tardif (2007) também ressalta que esses conhecimentos exigem autonomia e discernimento por parte dos profissionais, não se tratando apenas de conhecimentos técnicos padronizados ou em formas de receitas, de aplicação de teoria 
em vez de produção de conhecimento. Ao contrário, os conhecimentos exigem uma parcela de improvisação, de ressignificação a situações novas e únicas, como algo que está sendo construído no processo de formação, e não apenas como algo a ser transmitido. Isso é, a formação continuada e o exercício da prática docente não implica tornar as situações de aprendizagem na especialização mecanicamente análogas às situações de aprendizagem típicas de seus alunos na educação básica.

A relação entre o saber do professor e sua atividade cotidiana não tem consciência explícita, segundo Tardif (2007), indicando que o saber-fazer pode ser mais amplo que o seu conhecimento discursivo e que "o saber é experienciado por ser experimentado no trabalho, ao mesmo tempo em que modela a identidade daquele que trabalha", e que não deve ser confundido com a ideia de experimentação, "perspectiva positivista e cumulativa do conhecimento", nem com a ideia experimental, "visão humanista, ao foro interior psicológico e aos valores pessoais." (TARDIF, 2007. p. 110).

Esses saberes são mobilizados no âmbito do trabalho docente e possuem características específicas, visto que a interação pedagógica parece ser "a tarefa em torno da qual se articulam e ganham sentido todos os saberes do professor" (TARDIF, 2007, p. 221), que exigem determinadas competências imensuráveis em seu agir.

Enunciados declaram questões que se referem às disciplinas, aos livros e materiais recebidos no curso de especialização, expressando que os mesmos existem e seria interessante revisitar lá (4) onde eles se encontram. Essa enunciação afirma que os materiais do curso podem estar longe de seu alcance, podem estar fora do seu uso diário no contexto da educação básica. Entretanto, já foi estudado, mas, por hora, arquivado ou esquecido; que serviu, que é bom, mas realmente não usa; como pode servir para analisar sua prática à medida que experimenta novas formas de interferências e estratégias, transformando e ampliando sua própria prática.

Não há negação dos aspectos teóricos do curso, mas nunca os evidenciam como ponto principal para seu trabalho, a medida que destacam nos excertos analisados, o saber de sua experiência, caminhada e vivência naquilo que já está em seu domínio, porém em relação a um novo fazer, no caso a educação especial, querem embasamento.

Os enunciados declaram que as professoras alunas tomam suas decisões diante daquilo com que se deparam concretamente em suas práticas. Então, não é em qualquer curso que vão buscar subsídios, é específico no que desejam aprender. 
Nesse sentido, Krahe (2007) destaca a relevância do conhecimento adquirido da experiência quando descreve sobre a simetria invertida, postulando a necessidade dos formadores valorizarem esses saberes. Os mesmos também são fundamentados no Parecer CNE/CP 09/2001, que apresenta um breve histórico sobre a formação de professores da educação básica, destacando que as mudanças no interior das escolas exigem também mudanças nos processos formativos. Este parecer faz alusão ao conceito de simetria invertida indicando a falta de coerência nesse processo:

A preparação do professor tem duas peculiaridades muito especiais: ele aprende a profissão no lugar similar àquele em que vai atuar, porém, numa situação invertida. Isso implica que deve haver coerência entre o que se faz na formação e o que dele se espera como profissional. (BRASIL, 2002, p. 30).

Entretanto, nem sempre há coerência entre o preparo dos professores no campo formativo e a sua prática pedagógica no espaço em que vai atuar como docente, assim como formato de disciplinas oferecidas nos cursos. Nessa perspectiva, Isaia e Bolzan (2011) afirmam que os

movimentos construtivos da aprendizagem docente, manifestados pela alternância pedagógica e pela resiliência docente nos permitem compreender a tessitura da docência. Tal processo é dinamizado pela atividade docente de estudo e pelo trabalho pedagógico, compreendidos como componentes intrínsecos aos processos formativos docentes, os quais envolvem princípios éticos, didáticos e pedagógicos comuns. (ISAIA; BOLZAN, 2011, p. 198, grifo das autoras).

Nessa mesma direção, Nóvoa (2011, p. 231) escreve que "não é fácil definir o conhecimento profissional: ele tem uma dimensão teórica, mas não é teórico; tem uma dimensão empírica, mas não é unanimemente produzido pela experiência." A ideia do autor português foi possível de constatar nos excertos ${ }^{4}$ a seguir:

As teorias são muitas, e para mim é significativo saber aproveitar aquilo que no momento considero importante na minha prática. A prática pedagógica, não pode ser pautada em uma única teoria, ela deve ser o conjunto daquilo que melhor se adapta à realidade em qual exercito minhas funções. (14).

${ }^{4}$ Os excertos dos dizeres das professoras alunas do curso de pós-graduação latu sensu Especialização em Educação Inclusiva serão apresentados em itálico, seguido de um número criado por mim para referir as mesmas. 
Nessa lógica, outra professora complementa que as diversas discussões e debates sobre as diversidades e o papel da escola, do professor, para atender os princípios básicos que sustentam a educação especial [...] São princípios norteadores muito simples, mas difíceis na prática. (3).

Com isso observamos que as professoras alunas necessitam retomar os movimentos construtivos da aprendizagem docente, na medida em que não compreendem suas próprias concepções, o que as leva, por vezes, a refletir somente sobre a aprendizagem de seus alunos, e não sobre suas próprias aprendizagens, considerando que "a prática coloca problemas para os quais há muitas respostas que não estão dadas" (GATTI; BARRETO; ANDRÉ, 2011, p. 43), como expressa a professora, ao afirmar o seguinte:

Eu coloquei no papel a minha experiência, que não era daquele ano, já era de mais tempo, sabe? Então eu coloquei em prática, para mim foi bem mais fácil, porque eu trabalhava assim, só mais um embasamento teórico, que me mais, me abriu mais horizontes. Mas eu já fazia aquilo, o que eu escrevi eu já fazia então, eu tive bastante segurança. (7).

Nesse excerto a professora aluna relativiza a transposição do saber acadêmico e o peso de sua experiência, justificando os movimentos no interior de sua prática, assegurando a posição ocupada em sua trajetória.

No bojo desse processo formativo da docência, que de certa forma se caracteriza por movimentos de ensinar e aprender, vão se construindo as aprendizagens da experiência que, segundo Isaia e Bolzan (2011, p. 189), correspondem "a um conjunto de experiências vividas pelos sujeitos/professores e que pela sua significância intra e intersubjetiva transformam-se em experiências formativas."

Esta perspectiva pode estar indicando uma forma que mais se aproxima da produção do conhecimento como experiência social, na medida em que as professoras alunas trazem suas dúvidas relativas à vivências experienciadas individualmente na educação básica, para o contexto coletivo no processo de formação.

As ações de formação continuada e a construção de práticas docentes no âmbito da educação básica parecem apontar para a ausência de uma discussão epistemológica sobre temas vinculados à educação especial, tal como o próprio conceito de educação especial, o diagnóstico, a deficiência, a formação de professores, 
as práticas pedagógicas com estes alunos, com base nos quais, se sustentam em práticas sociais.

Além disso, fundamentos específicos do campo da educação especial, apesar de terem sido contemplados na formação continuada, não geraram efeitos na prática docente com os alunos que apresentam deficiências específicas. Percebo que a ideia que as professoras alunas fazem da formação está diretamente relacionada com suas vivências no contexto da educação básica, projetando assuntos que precisariam ser aprofundados, como temática importante para todos os professores que atuam no contexto da educação especial.

Estes fundamentos abrangem uma compreensão teórica e conceitual de temas ligados à educação especial que as professoras alunas por vezes destacam, por outras rejeitam. Contudo, considerando as necessidades do momento, há depoimentos que produzem crescimento pessoal e/ou profissional, causando efeitos para a prática docente.

\section{CONSIDERAÇÕES FINAIS}

Frente aos tensionamentos evidenciados nos conjuntos discursivos, 0 argumento principal desse estudo direciona para a afirmação de que os saberes produzidos, ressignificados e/ou refletidos, no curso de formação continuada em educação especial, aqui analisados, no que se refere à prática de educação inclusiva, para decisão pedagógica, é uma ação complexa no contexto da educação básica e exige saberes de diferentes naturezas, que vão além do campo epistemológico e prático, pois incluem aqueles que estão alicerçados na cultura de cada docente.

Nesse contexto, o desafio posto reside na possibilidade de construir ações oferecidas pelas esferas públicas, visando maior organicidade dos sistemas de ensino para garantir as políticas de valorização docente, associadas à formação continuada, salários, carreira e desenvolvimento profissional.

Essas reflexões não implicam em abandonar o debate. Todavia perseguem uma perspectiva acerca das políticas educacionais, com proposições atuais para educação especial na educação básica. Estas em sua relação com a formação continuada de professores, visando a que se possa marcar o lugar ocupado pela docência nos discursos políticos e, assim, possibilitando apreender a constituição dos 
sentidos, articulados e propostos enquanto texto, enquanto práticas discursivas e enquanto práticas sociais.

\section{REFERÊNCIAS}

BRASIL. Conselho Nacional de Educação. Câmara de Educação Básica. Parecer CNE/CP n. 09/2001. Institui Diretrizes Curriculares Nacionais para a Formação de Professores da Educação Básica, em nível superior, curso de licenciatura, de graduação plena. Diário Oficial da União, em 18 jan. 2002.

BRASIL, Ministério da Educação. Secretaria de Educação Especial. Política Nacional de Educação Especial na Perspectiva da Educação Inclusiva. Documento elaborado pelo Grupo de Trabalho nomeado pela Portaria nำ555/2007, prorrogada pela Portaria no 948/2007, entregue ao Ministro da Educação em 07 de janeiro de 2008. Brasília, DF.

BRASIL. Portaria n. 09/2009, de 30 de junho de 2009. Institui o Plano Nacional de Formação dos Professores da Educação Básica, no Âmbito do Ministério da Educação. Diário Oficial da União, 1ํjun. 2009.

GATTI, B. A.; BARETTO, E.S.S.; ANDRÉ, M. A. Políticas Docentes no Brasil: um estado da arte. Brasília: UNESCO, 2011.

GUASSELLI, Maristela F. R. Formação continuada na perspectiva da educação inclusiva: Epistemologia e prática / Maristela Ferrari Ruy Guasselli. -- 2014 Tese (Doutorado) -- Universidade Federal do Rio Grande do Sul, Faculdade de Educação, Programa de Pós-Graduação em Educação, Porto Alegre, BR-RS, 2014.

ISAIA. S.M.A, e BOLZAN, A.M.R.M. Tessituras Formativas: articulação entre movimentos da docência e da aprendizagem docente. In: Qualidade da educação superior: a universidade como lugar de formação [recurso eletrônico] / organizadora, Silvia Maria de Aguiar Isaia; colaboradoras, Doris Pires Vargas Bolzan, Adriana Moreira da Rocha Maciel. - Dados eletrônicos. - Porto Alegre: EDIPUCRS, 2011.

KRAHE, Elizabeth D. Sete décadas de tradição: ou a difícil mudança de racionalidade da pedagogia universitária nos currículos de formação de professores. In: FRANCO, M.E.D.P.; KRAHE E.D. Pedagogia Universitária e áreas de conhecimento. Porto Alegre: EDIPUCRS, 2007

NÓVOA, Antonio. O professor pesquisador e reflexivo. Entrevista concedida em 13 setembro de 2001. Disponível em:

$<$ http://www.tvbrasil.org.br/saltoparaofuturo/entrevista.asp?cod_Entrevista=59>.

Acesso em: 10 ago. 2012.

NÓVOA, Antonio. Os professores e o "novo" espaço público da educação. In: TARDIF M. e LESSARD C. O Ofício de professor. História, perspectivas e desafios internacionais. Petrópolis, RJ: Vozes, 2011. 
TARDIF, Maurice. Saberes docentes e formação profissional. Petrópolis, RJ: Vozes, 2007. 